\section{SM Tropical Medicine Journal}

\section{Article Information}

Received date: Jun 02, 2016

Accepted date: Jul 15, 2016

Published date: Jul 19, 2016

*Corresponding author

Sung-Hsi Wei, Department of Public Health, China Medical University, Taiwan (R.O.C.), Email: epediat@gmail.com

Distributed under Creative Commons CC-BY 4.0

Keywords Swimming Pool; Adenovirus; Taiwan; Tropical; Conjunctivitis

Article DOI 10.36876/smtmj.1007

\title{
An Adenovirus Outbreak Associated with a Swimming Facility
}

\author{
Sung-Hsi Wei ${ }^{1,2 *}$ \\ ${ }^{1}$ Department of Public Health, China Medical University, Taiwan (R.O.C) \\ ${ }^{2}$ Department of Emergency, China Medical University Children's Hospital, Taiwan (R.O.C)
}

\section{Abstract}

Adenovirus outbreaks have been reported to be associated with recreational water over the past decades. An outbreak of respiratory tract infection in a primary school in central Taiwan occurred in September 2011. The laboratory tests showed that it was an outbreak of adenovirus infection. Epidemiological investigations revealed that the outbreak was associated with a swimming facility outside the school. Our report emphasized the potential threat of adenovirus infection associated with swimming facilities, especially in a community adenovirus epidemic setting.

\section{The study}

Adenovirus is a double-stranded DNA virus that infects hosts across a broad spectrum of vertebrates [1]. Since its first isolation from human adenoid tissue and named for the tissue of origin in 1953, there have been more than 50 genotypes identified worldwide [2,3]. Adenovirus infection causes a variety of diseases with some genotype predisposition, including conjunctivitis, gastroenteritis, respiratory tract infection, and cystitis $[4,5]$. The clinical presentation ranges from mild self-limited illness to fatal infection [6]. A primary adenovirus infection may convey genotypespecific lifelong immunity to the human host [7].

Adenovirus was one of the major viral pathogens associated with acute respiratory tract conditions. It has been reported to be the most common agent associated with pharyngitis and tonsillitis in Taiwan [8]. Adenovirus genotype 3 was the predominant genotype in Taiwan in the past 3 decades $[9,10]$. An epidemic of adenovirus infection occurred in Taiwan in 2011. The predominant genotypes associated with the epidemic were genotype 3 and genotype 7 , which was rarely isolated from clinical specimens in the preceding years in Taiwan and was associated with severe clinical manifestation [10-12].

Adenovirus outbreak associated with swimming pool water was first reported in the 1950s $[13,14]$. In recent decades it was reported to be the $2^{\text {nd }}$ largest cause of outbreaks associated with recreational water in the literature [15]. However, most of the outbreaks occurred in western countries above 40 degrees of latitude $[15,16]$. Here, we report an outbreak of adenovirus infection associated with swimming in Taiwan, a tropical and subtropical country in Asia.

The public health authority was notified of a respiratory tract infection outbreak in a primary school in central Taiwan on September 15, 2011. The affected students presented with fever and symptoms of upper respiratory tract infection from early September. After the outbreak was identified, the affected students were encouraged to take sick leaves or to use surgical masks on campus. Moreover, school staff was asked to use bleach to disinfect the desks and chairs daily in classes where affected students might have contacted.

To use the laboratory resources efficiently, public health authorities were requested to submit no more than 10 specimens for one outbreak for laboratory investigation by Taiwan Centers for Disease Control. Ten throat swabs of affected students were submitted to the laboratory in Taiwan Centers for Disease Control for etiological study. The multiplex real-time Polymerase Chain Reaction (PCR) technique was used to detect potential pathogens including influenza virus, adenovirus, respiratory syncytial virus, coronaviruses (229E, OC43, NL63, HKU1, MERS-CoV), metapneumovirus, parainfluenza type 1-4, and herpes simplex virus [17-22]. All 10 students tested positive for adenovirus and negative for the other viruses. Because genotype was associated with clinical manifestation and severity for adenovirus infection, another PCR genotype analysis was conducted targeting a 956-bp region of the adenovirus hexon gene to study the genotype, with all 10 samples testing positive for adenovirus genotype 7 [23]. The majority of the affected students were $5^{\text {th }}$ and $6^{\text {th }}$ graders who had swimming class in two swimming facilities, Facility A and Facility $\mathrm{B}$, outside the school. The preliminary investigation showed that the incidence of illness seemed higher in the classes in which students attended swimming class in Facility A than that in Facility 


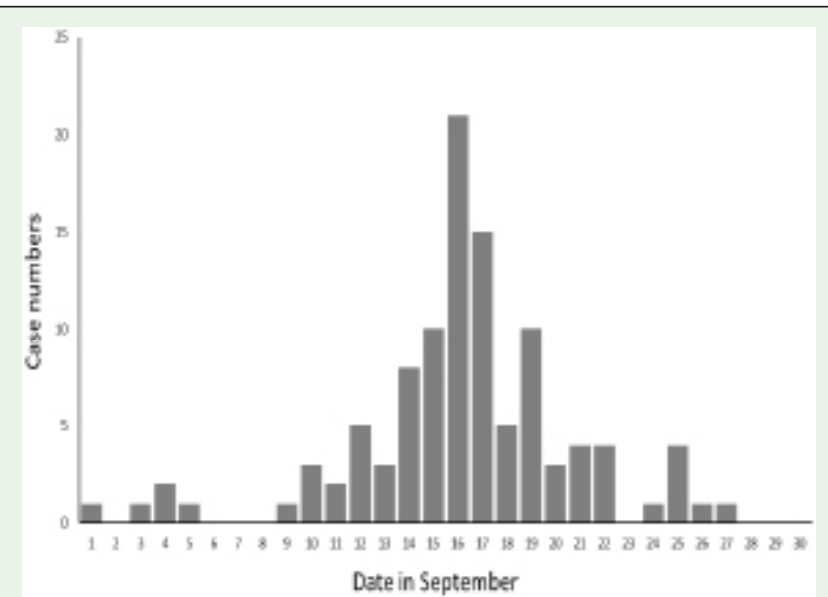

Figure 1: Case numbers with regard to the onset of illness, Taiwan, September $2011(n=106)$.

B. The swimming class was temporarily suspended to prevent further outbreak. Public health personnel obtained the regular test results performed by the county government in August 11, 2011 and found the chlorine level was 2.8 and 2.3 parts per million (ppm) in Facilities $\mathrm{A}$ and $\mathrm{B}$, respectively. The maintenance logs in both facilities were inspected and both showed the daily chlorine level measured by the facility staff to be between 1.0 to $2.0 \mathrm{ppm}$ in August and September. No record of chlorine level less than $1.0 \mathrm{ppm}$ had been identified in either facility. Because of logistic barriers, water samples were not obtained from either facility for virological or chlorine level analysis.

Between September $26^{\text {th }}$ and $30^{\text {th }}$, a paper-and-pencil questionnaire was initiated among the $5^{\text {th }}$ and $6^{\text {th }}$ graders to explore the clinical manifestation and epidemiological features of the outbreak. The case definition in the outbreak was defined as concurrent presence with fever and one of the following respiratory tract infection symptoms in September 2011: cough, sore throat, headache, rhinorrhea, nausea or vomiting, diarrhea, conjunctivitis, or skin eruption. Fever was defined as a measured body temperature of greater than 37.5 degrees Celsius.

Of the 385 students in grade 5 and grade 6, 373 (96.9\%) completed the questionnaire. Of the 373 students, 112 (30.0\%) developed fever and $106(28.4 \%)$ satisfied the requirements of the case definition. With regard to the onset of illness, the case number peaked on September 16th and gradually decreased stepwise thereafter (Figure 1). In addition to fever, case students presented with sore throat (80/106, 75.5\%), headache $(65 / 106,61.3 \%)$, cough $(55 / 106,51.9 \%)$, rhinorrhea $(51 / 106,48.1 \%)$, diarrhea $(42 / 106,39.6 \%)$, vomiting $(22,20.8 \%)$, skin eruption $(5 / 106,4.7 \%)$, and conjunctivitis $(3 / 106$, $2.8 \%)$. Sixty-nine (65.1\%) of the 106 case patients had taken sick leave and $4(3.8 \%)$ had been hospitalized. All the case patients recovered

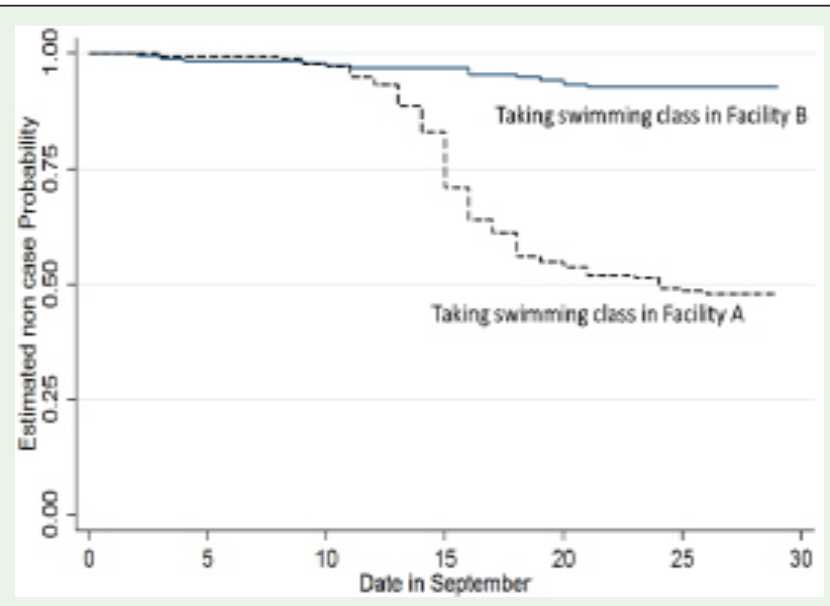

Figure 2: Kaplan Meier survival curves of cases taking swimming class in Facility A and Facility B.

completely without long-term sequelae. Survival analysis with Stata software (version 13, Stata Corp LP, College Station, Texas, USA) was carried out for risk factor analysis. Potential risk factors included the facilities in which students attended swimming class, gender, and grade. Taking swimming class in Facility A was the only risk factor significantly associated with becoming case students in univariate and multivariate analysis $(\mathrm{p}<0.001)$ (Table 1$)$. Kaplan-Meier survival curves were constructed based on taking swimming class in the facilities (Figure 2).

Our investigation demonstrated that the outbreak was associated with attending swimming class in Facility A, of which the maintenance log showed the chlorine level was between 1.0 to $2.0 \mathrm{ppm}$ in August and September. The result was inconsistent with a previous review that $69 \%$ of swimming pool outbreaks were associated with inadequate chlorination with free chlorine less than 1 ppm [15]. Harley has reported an adenovirus outbreak associated with a swimming pool which chlorine concentration was $1.0 \mathrm{ppm}$ [24]. Because the chlorine might be exhausted within hours in hot days, the common circumstances in tropical countries, he asserted a chlorine concentration of not less than $2.0 \mathrm{ppm}$ would be appropriate [24]. In addition, the records in the maintenance log were maintained by the facility staff and were obtained days after the outbreak was identified, resulting in the disputable credibility of the records in both facilities. The water used in the shower room might also have contributed to the adenovirus infection. However, no records for the chlorine level of shower water in either facility were available during the investigation.

During swimming class, students might contract adenovirus infection through direct contact with contaminated water or

Table 1: Univariate and multivariate analysis of potential risk factors for becoming case students in the outbreak.

\begin{tabular}{|c|c|c|c|c|c|c|c|c|}
\hline \multirow{2}{*}{ characteristics } & \multirow{2}{*}{$\begin{array}{c}\text { Case }(n=106) \\
(\%)\end{array}$} & \multirow{2}{*}{$\begin{array}{l}\text { Non-case } \\
(n=267)(\%)\end{array}$} & \multicolumn{3}{|c|}{ Univariate analysis } & \multicolumn{3}{|c|}{ Multivariate analysis } \\
\hline & & & Hazard ratio & $95 \% \mathrm{Cl}^{*}$ & pvalue & Hazard ratio & $95 \% \mathrm{Cl}^{*}$ & pvalue \\
\hline Facility A & $92(86.8)$ & $86(32.2)$ & 9.33 & $5.31-16.39$ & $<0.001$ & 9.62 & $5.46-16.96$ & $<0.001$ \\
\hline Male & $56(52.8)$ & $143(53.6)$ & 0.99 & $0.68-1.45$ & 0.96 & 1.18 & $0.81-1.74$ & 0.39 \\
\hline Grade 5 & $54(50.9)$ & $143(53.6)$ & 0.99 & $0.67-1.45$ & 0.96 & 1.16 & $0.79-1.71$ & 0.44 \\
\hline
\end{tabular}

${ }^{*} \mathrm{Cl}$ indicates Confidence Interval. 
inhalation of aerosolized droplets from the swimming pool. The increasing number of infected children might further increase the outbreak scale exponentially when they attended the swimming class in facility A. Students who attended swimming class in Facility A attended other classes together in school, potentially further facilitating droplet transmission through close contact with case students. In addition to swimming class suspension in the swimming facilities, taking sick leaves or using surgical masks on campus might halt the adenovirus transmission, contributing to the decrease in number of cases since September $16^{\text {th }}$.

The laboratory tests demonstrated that the outbreak was associated with adenovirus genotype 7 , which had caused an epidemic in Asia between 2011 and 2013 [10,16,25]. Previous study showed that the hexon gene sequences had high similarity among that of adenovirus isolated in Singapore, China, and Taiwan during the aforementioned epidemic [25]. Although adenovirus genotype 7 has been implicated in severe infection in the community epidemic setting, the case students in our outbreak did not present with severe clinical manifestation and all recovered completely [10].

Our report was limited by the low number of clinical specimen tested and absence of laboratory investigation for swimming pool water; nevertheless, our report emphasized the potential threat of adenovirus infection associated with swimming facilities, especially in a community adenovirus epidemic setting.

\section{References}

1. Davison AJ, Benko M, Harrach B. Genetic content and evolution of adenoviruses. The Journal of general virology. 2003; 84: 2895-2908.

2. Rowe WP, Huebner RJ, Gilmore LK, Parrott RH, Ward TG. Isolation of a cytopathogenic agent from human adenoids undergoing spontaneous degeneration in tissue culture. Proceedings of the Society for Experimental Biology and Medicine Society for Experimental Biology and Medicine (New York, NY). 1953; 84: 570-573

3. Jiang SC. Human adenoviruses in water: occurrence and health implications: a critical review. Environmental science \& technology. 2006; 40: 7132-7140.

4. Dawson CR, O'Day D, Vastine D. Letter: Adenovirus 19, a cause of epidemic keratoconjunctivitis, not acute hemorrhagic conjunctivitis. The New England journal of medicine. 1975; 293: 45-46.

5. Brandt CD, Kim HW, Vargosko AJ, Jeffries BC, Arrobio JO, Rindge B, et al Infections in 18,000 infants and children in a controlled study of respiratory tract disease. I. Adenovirus pathogenicity in relation to serologic type and illness syndrome. American journal of epidemiology. 1969; 90: 484-500.

6. Zhang SY, Luo YP, Huang DD, Fan H, Lu QB, Wo Y, et al. Fatal pneumonia cases caused by human adenovirus 55 in immunocompetent adults. Infectious diseases (London, England). 2016; 48: 40-47.

7. Fox JP, Brandt CD, Wassermann FE, Hall CE, Spigland I, Kogon A, et al. The virus watch program: a continuing surveillance of viral infections in metropolitan New York families. VI. Observations of adenovirus infections: virus excretion patterns, antibody response, efficiency of surveillance, patterns of infections, and relation to illness. American journal of epidemiology. 1969; 89: 25-50.

8. Tsai HP, Kuo PH, Liu CC, Wang JR. Respiratory viral infections among pediatric inpatients and outpatients in Taiwan from 1997 to 1999. Journal of clinical microbiology. 2001; 39: 111-118.

9. Lin YC, Lin KH, Ke GM, Lee MS, Lin PC, Liu HF, et al. Secular trend of genome types of respiratory adenovirus type 3 during 1983-2005: a study from Taiwan. Archives of virology. 2010; 155: 287-292.
10. Tsou TP, Tan BF, Chang HY, Chen WC, Huang YP, Lai CY, et al. Community outbreak of adenovirus, Taiwan, 2011. Emerging infectious diseases. 2012; 18: $1825-1832$

11. Lin YC, Lu PL, Lin KH, Chu PY, Wang CF, Lin JH, et al. Molecular Epidemiology and Phylogenetic Analysis of Human Adenovirus Caused an Outbreak in Taiwan during 2011. PloS one. 2015; 10: e0127377.

12. Yamamoto D, Okamoto M, Lupisan S, Suzuki A, Saito M, Tamaki R, et al. Impact of human adenovirus serotype 7 in hospitalized children with severe fatal pneumonia in the Philippines. Japanese journal of infectious diseases. 2014; $67:$ 105-110.

13. Ormsby HL, Aitchison WS. The role of the swimming pool in the transmission of pharyngeal-conjunctival fever. Canadian Medical Association journal. 1955; 73: 864-866.

14. Cockburn TA. An epidemic of conjunctivitis in Colorado associated with pharyngitis, muscle pain, and pyrexia. American journal of ophthalmology. 1953; 36: 1534-1539.

15. Sinclair RG, Jones EL, Gerba CP. Viruses in recreational water-borne disease outbreaks: a review. Journal of applied microbiology. 2009; 107: 1769-1780.

16. Xie L, Yu XF, Sun Z, Yang XH, Huang RJ, Wang J, et al. Two adenovirus serotype 3 outbreaks associated with febrile respiratory disease and pharyngoconjunctival fever in children under 15 years of age in Hangzhou, China, during 2011. Journal of clinical microbiology. 2012; 50: 1879-1888.

17. Yang JR, Lo J, Liu JL, Lin CH, Ho YL, Chen CJ, et al. Rapid SYBR green $\mathrm{I}$ and modified probe real-time reverse transcription-PCR assays identify influenza $\mathrm{H} 1 \mathrm{~N} 1$ viruses and distinguish between pandemic and seasonal strains. Journal of clinical microbiology. 2009; 47: 3714-3716.

18. Gunson RN, Collins TC, Carman WF. Real-time RT-PCR detection of 12 respiratory viral infections in four triplex reactions. Journal of clinical virology: the official publication of the Pan American Society for Clinical Virology. 2005; 33: 341-344.

19. Ward CL, Dempsey MH, Ring CJ, Kempson RE, Zhang L, Gor D, et al. Design and performance testing of quantitative real time PCR assays for influenza $A$ and $B$ viral load measurement. Journal of clinical virology: the official publication of the Pan American Society for Clinical Virology. 2004; 29: $179-188$

20. Karatas H, Gurer G, Pinar A, Soylemezoglu F, Tezel GG, Hascelik G, et al. Investigation of HSV-1, HSV-2, CMV, HHV-6 and HHV-8 DNA by real-time $\mathrm{PCR}$ in surgical resection materials of epilepsy patients with mesial temporal lobe sclerosis. Journal of the neurological sciences. 2008; 264:151-156.

21. Chidlow GR, Harnett GB, Shellam GR, Smith DW. An economical tandem multiplex real-time PCR technique for the detection of a comprehensive range of respiratory pathogens. Viruses. 2009; 1: 42-56

22. Wei SH, Yang JR, Wu HS, Chang MC, Lin JS, Lin CY, et al. Human infection with avian influenza A H6N1 virus: an epidemiological analysis. The Lancet Respiratory medicine. 2013; 1: 771-778.

23. Heim A, Ebnet C, Harste G, Pring-Akerblom P. Rapid and quantitative detection of human adenovirus DNA by real-time PCR. Journal of medical virology. 2003; 70: 228-239.

24. Harley D, Harrower B, Lyon M, Dick A. A primary school outbreak of pharyngoconjunctival fever caused by adenovirus type 3 . Communicable diseases intelligence. 2001; 25: 9-12.

25. Ng OT, Thoon KC, Chua HY, Tan NW, Chong CY, Tee NW, et al. Severe Pediatric Adenovirus 7 Disease in Singapore Linked to Recent Outbreaks across Asia. Emerging infectious diseases. 2015; 21: 1192-1196. 